Running head: PARTISANS’ IDENTITY FUSION

Temporal Dynamics of Partisan Identity Fusion and Prosociality during the 2016 U.S. Presidential Election

Antonia Misch $^{\mathrm{a}, \mathrm{b}}$, Grant Fergusson ${ }^{\mathrm{a}}, \&$ Yarrow Dunham ${ }^{\mathrm{a}}$

${ }^{a}$ Department of Psychology, Yale University, New Haven, CT, USA

${ }^{b}$ Department of Psychology, Ludwig Maximilian University, Munich, Germany

Word Count: 6213 (excluding abstract and figure captions)

In press, Self and Identity

Corresponding Author:

Antonia Misch

Department of Psychology

Ludwig Maximilian University

Leopoldstr. 13

80802 Munich

Germany

e-mail: antonia.misch@psy.lmu.de

phone: +49 (89) 21806048 


\title{
PARTISANS' IDENTITY FUSION 2
}

\begin{abstract}
We investigated the dynamics of identity fusion and prosocial behavior within political groups in the four weeks preceding and following the 2016 U.S. Presidential Election. The primary questions were whether a negative event (losing) would lead to a more pronounced increase in identity fusion, and whether identity fusion would predict prosocial giving. We found that while fusion gradually increased in the run-up to the election, there was no significant increase after the event for supporters of either party. We also found that identity fusion robustly predicted prosocial ingroup giving, especially before the election, and even when accounting for self-reported identification and previous political commitment behaviors. Implications for theories of identity fusion are discussed.
\end{abstract}

Keywords: identity fusion, prosociality, dictator game, presidential election

This work was enabled by the generous support of the John Templeton Foundation (Grant No. 56036). 
PARTISANS' IDENTITY FUSION 3

\section{Partisans' Identity Fusion and Prosociality during the 2016 Presidential Election}

The zeal with which humans engage in costly cooperation remains one of the most striking phenomena in the behavioral sciences. At the extreme, individuals are sometimes willing to risk and even sacrifice their own life to help their groups (e.g., Atran, Sheikh, \& Gomez, 2014; Fredman et al., 2015; Swann, Gomez, Dovidio, Hart, \& Jetten, 2010; Swann et al., 2014; Whitehouse, McQuinn, Buhrmester, \& Swann, 2014), as with soldiers in times of war and voluntary organ donors. Less extreme but still costly behavior is much more frequent, as with donating time and money to needy others or favored causes. When such cooperation occurs between biologically related others, evolutionary explanations are readily available (see Hamilton, 1964; Henrich, 2004; Nowak, 2006; Simpson \& Beckes, 2010), but such cooperation also occurs between unrelated others and is even directed at extended groups in which the cooperating individual may not know every member. What drives such behavior?

Swann and colleagues offer a psychological and motivational explanation via the concept of identity fusion: a feeling of deep connection with others who share salient social identities (Swann, Gómez, Seyle, Morales, \& Huici, 2009). A strong alignment between a personal and social self is also at the heart of the more familiar construct of group identification (Social Identity Theory; Tajfel \& Turner, 2004). But that perspective generally assumes that even among the highly identified the personal and social selves remain distinct. By contrast, identity fusion argues that in some cases the lines between the self and the group are blurred, such that actions benefitting the group are literally conceptualized by the individual as benefitting the self. This view has the advantage of offering a simple explanation for even quite extreme sacrifice for a group: defending the group is actively conceptualized as defending the self (Swann \& Buhrmester, 2015).

Supporting this perspective, several studies have found that identity fusion fosters extreme ingroup behavior, including the willingness to fight and die for one's country (Besta, Gómez, \& Vázquez, 2014; Swann et al., 2010; Swann, Gómez, Huici, Morales, \& Hixon, 2010; Swann et al., 2014; Whitehouse et al., 2017), as well as less extreme behavior like ingroup helping (Buhrmester, Fraser, Lanman, Whitehouse, \& Swann, 2015; Gómez, Morales, Hart, Vázquez, \& Swann, 2011). 
Further, measures of identity fusion consistently outperform measures of group identification when predicting self-sacrifice or fighting for the group (Gómez, Brooks, et al., 2011; Swann et al., 2009; Swann, Gómez, Dovidio, et al., 2010; Swann, Gómez, Huici, et al., 2010).

What factors lead to identity fusion? Evolutionary-minded accounts (Swann, Jetten, Gómez, Whitehouse, \& Bastian, 2012) propose that the psychology behind identity fusion functions to enable extreme helping behaviors toward kin. However, under some circumstances this same psychology is projected onto close non-kin. Supporting this account, identity fusion is predicted by the level of genetic relatedness in monozygotic and dizygotic twins (Vázquez, Gómez, Ordoñana, Swann, \& Whitehouse, 2017), and the subjective sense of holding familial ties with a group mediates the association between fusion and pro-group behavior in unrelated individuals (Atran et al., 2014; Buhrmester et al., 2015; Swann et al., 2014; Whitehouse et al., 2014). A complementary perspective comes from anthropological accounts, which argue that fusion increases when significant or extreme events become powerful shared memories and thus shared history within a group (Whitehouse et al., 2017). In the most extreme cases these bonds override individuals' self-preservation, enabling highrisk collective activities to benefit the group (Whitehouse \& Lanman, 2014), especially in times of threat (Gómez, Morales, et al., 2011) or intergroup competition (Whitehouse et al., 2017). Thus, the psychology of identity fusion is tuned to functional ends: bringing the group together in times of need. Research from beyond the lab also supports this perspective: the co-experience of traumatic events predicted higher levels of identity fusion after the Boston Marathon bombing (Jong, Whitehouse, Kavanagh, \& Lane, 2015) and in front line fighters in the Libyan revolution (Whitehouse et al., 2014). Social support increased in survivors of the Virginia Tech shooting (Mancini, Littleton, \& Grills, 2015) and in children who survived an earthquake (Vezzali, Drury, Versari, \& Cadamuro, 2015). Whitehouse and colleagues point to the specific role of dysphoric experiences as facilitators of identity fusion (2017), claiming that dysphoric rituals in some traditional small scale societies serve as ways to promote identity fusion and thus cooperation (Whitehouse, 2012; Whitehouse \& Lanman, 2014; Whitehouse \& McQuinn, 2013). 
Less threatening but nonetheless salient experiences also support identity fusion. For example, identity fusion and prosocial ingroup giving was higher in supporters of a soccer team that lost as compared to won a match (Whitehouse et al., 2017), and experimentally inducing pain in the lab (e.g., by asking participants to hold their hands in icy water) also increased bonding between participants (Bastian, Jetten, \& Ferris, 2014). Other findings have suggested that positive events can also foster identity fusion. For example, in one study both victory and defeat for fans of a football club led to higher levels of identity fusion (Newson, Buhrmester, \& Whitehouse, 2016; see also Evans \& Dion, 1991; Mullen \& Copper, 1994). Thus, a critical question is whether negative experiences are more likely to foster identity fusion and prosocial behavior, and whether previously reported results hold across events that vary in their severity.

One promising approach to answering this question involves measuring identity fusion in the context of dynamic real-world events. For example, Vazquez and colleagues investigated how identity fusion with the country changed in Spaniards after a corruption scandal involving the Royal family and a referendum about the potential independence of Catalonia, a region in the Northeast of Spain (Vázquez, Gómez, \& Swann, 2017). All of these events were salient negative events that threatened the integrity of Spanish national identity. Surprisingly, they found that levels of identity fusion decreased in highly fused individuals after these events (though their stated willingness to die and fight for the group remained the same). The authors explained this finding by arguing that fusion operates differently when the threats to the group came from within the group itself, rather than from an outgroup. Still, these findings demonstrate that negative events do not always lead to greater fusion, and that at least some factors that affect fusion do not directly affect orientation towards prosocial group behavior.

In the research reported here, we took advantage of a naturally occurring, large-scale, and highly salient event in which two powerful social collectives were engaged in competition, followed by a victory for one of the collectives and a defeat for the other: the 2016 U.S. Presidential Election. Elections are not as extreme, traumatic, or life-threatening as natural disasters, wars, or terror attacks, but they can have a large influence on the political, social, and economic course of a nation. Further, 
at least in the contemporary American context, they are both highly publicized and highly polarized, making it very likely that identity-relevant cognition will be active for most observers. Thus, we would argue that they fall somewhere between the lower-stakes context of a soccer game or political scandal, which are unlikely to elicit identity-relevant cognition from most observers, and the higherstakes context of true collective trauma like natural disasters or wars. More generally, past research suggests that elections are highly important events for many people, and their outcomes directly affect levels of happiness and sadness for supporters of the defeated party (Pierce, Rogers, \& Snyder, 2016) as well as levels of the stress hormone cortisol (Blanton, Strauts, \& Perez, 2012). Further, individuals who are fused with a party perceive their personal life quality as directly connected to the election outcome (Buhrmester et al., 2012). The all-or-nothing context of the U.S. Presidential Election presented us with the opportunity to examine the impact of both positive and negative events in the same design by including supporters of both major candidates. Thus, in the current preregistered study, we investigated identity fusion in the context of a less extreme but nonetheless salient and consequential form of "traumatic" event: being part of the winning versus losing party in a major national election.

To assess the dynamics of identity fusion before and after the "shock" of the election itself, we measured partisan identity fusion in a multi-wave, cross-sectional design. Every 6 days, we surveyed a distinct pool of around 300 participants, totaling 10 waves of data collection from approximately 4 weeks before to 4 weeks after the election on November 8, 2016. A considerable portion of the American electorate bases their electoral decisions on candidate factors rather than on party factors (e.g., Barker, Lawrence, \& Tavits, 2006; Rapoport, 1997; Wattenberg, 1987). This was particularly true during the 2016 election, in which many partisans did not initially support - and may have even strongly opposed - their party's eventual nominee (see, e.g., Enten, 2016; Kludt, 2016). To ensure that we would capture differences along these lines, we measured identity fusion both with one's party and with supporters of one's preferred candidate. To connect identity fusion to prosocial behavior, we also included a standard measure of prosocial giving, the Dictator Game (e.g., Forsythe, Horowitz, Savin, \& Sefton, 1994; Franzen \& Pointner, 2013; Kahneman, Knetsch, \& Thaler, 1986), in 
which participants receive a monetary endowment that they can either keep or share with a supporter of their same presidential candidate.

In line with research showing that identity fusion with a group increases after a painful or traumatic event (Jong et al., 2015; Whitehouse et al., 2014, 2017), our primary hypothesis was that the "event shock" of losing the election would be associated with increased levels of identity fusion in partisans of the losing party after the election, relative to levels of identity fusion before the election (in this case the Democratic Party, though the outcome was unknown at the time). Because our design was cross-sectional, we cannot speak directly to intrapersonal change over time; instead, we infer changes in identity fusion from cross-sectional differences in identity fusion across time points. As always with cross-sectional data, inferences to intrapersonal change and the causal impact of the election should be made cautiously. For partisans of the winning party (as it happened, the Republican Party), we did not have a strong prediction, but expected that if identity fusion would increase after the election, the relative increase would be weaker than in the losing party, based on previous research finding higher levels of fusion after negative compared to positive events (e.g., Whitehouse et al., 2017). Our secondary prediction was that identity fusion would be a stronger predictor of ingroup prosocial giving than standard measures of social identification. To briefly forecast our results, while the data were broadly consistent with an increase in identity fusion leading up to the election, they were more consistent with a gradual positive change rather than a sudden increase following the "shock" of the election outcome. Further, we did not observe larger increases in identity fusion in the defeated party. Thus, our primary hypothesis was not supported. However, our secondary hypothesis, that identity fusion is an important predictor of prosocial giving, was supported.

\section{Method}

\section{Participants}

Our two primary analyses and sample size determinations were pre-registered prior to data collection at https://aspredicted.org/7q4ba.pdf. Between October 12 and December 5, 2016, we surveyed a distinct pool of 300 participants via Amazon Mechanical Turk every 6 days, resulting in 10 waves of data collection (total $N=3022$ ); respondents from prior waves of the survey were blocked 


\section{PARTISANS' IDENTITY FUSION 8}

from participating repeatedly. After eliminating cross-party voters (who were not numerous enough to be independently analyzed), non-U.S. citizens, incomplete responses (who did not finish both identity fusion tasks), and participants who failed to complete a simple compliance check (correctly transcribing the first sentence of a short handwritten text), our final sample consisted of 2699 participants; 1732 identified as Democrats ( $55 \%$ women, $42 \%$ men; mean age $=35.85, S D=11.91$ ) and 967 as Republicans (47\% women, 50\% men, mean age $=38.6, S D=12.47$ ), who all supported the candidate nominated by their favored party.

\section{Procedure}

In exchange for a 70-cent show-up fee and the possibility of earning an additional bonus (described below), participants answered a ten-minute Qualtrics survey about "preferences for political parties and presidential candidates", altered slightly for pre- and post-election conditions. The survey assessed (1) their preference for political party and candidate; (2) their self-reported identification with and support of a political party and candidate; (3) identity fusion with a political party and supporters of a candidate; (4) prosocial ingroup giving towards a fellow supporter of their favored candidate; and (5) a series of demographic items.

After indicating their political party preference and candidate preference ("Do you prefer the Democratic or the Republican Party?", "Which candidate did you prefer in the general election?"), participants answered a set of questions regarding their preferred political party (party identification/support) and another set of questions regarding their preferred candidate (candidate support) in counterbalanced order. Party identification and candidate support were assessed using 7point Likert scales ("How strongly do you identify with...?" and "How strongly do you support...?"), and previous commitment was measured with additional questions about their party registration, primary candidate support, and party and candidate directed donations and volunteering behavior. Identity fusion was measured using the Dynamic Identity Fusion Index (DIFI; Jiménez et al., 2016), a continuous measure of the pictorial item scale of identity fusion (Swann et al., 2009) in which participants indicate their relationship with the group by dragging a smaller "Me Circle" horizontally towards a bigger "Group Circle", which was either labeled as "Democratic Party" or "Republican 
Party" for the party fusion measure and "Clinton Supporters" and "Trump Supporters" for the candidate fusion measure. The distance the circle was moved and the overlap of the two circles serves as the index of identity fusion.

In the dictator game, participants were paired with another participant who shared both their preferred presidential candidate and political party. Participants were informed that they would choose how many of 40 cents to keep or transfer to the other subject along 5 cent intervals, and subsequently asked to explain their choice. The study did not involve deception; after each wave, participants were randomly matched with another participant who fit the necessary criteria and bonuses were paid out in accordance with actual dictator game transfers.

Finally, to ensure that the election was an emotionally impactful event, we assessed the impact of the event on participants' happiness. Before the election, we asked them to indicate their levels of happiness for both possible event outcomes on a Likert scale ("How would you feel if Donald Trump/Hillary Clinton won the general election?"; 1 = very unhappy; 7 = very happy). After the election, we asked them to indicate their levels of happiness as a result of the outcome for their preferred party (i.e., supporters of Hillary Clinton were asked: "How do you feel now that Hillary Clinton lost the general election?", and supporters of Donald Trump were asked: "How do you feel now that Donald Trump won the general election?"; 1 = very unhappy; 7 = very happy).

\section{Results}

\section{Preliminary Analysis}

Identity Fusion

Because the two measures of identity fusion (overlap between the two circles and distance the small circle was moved towards the larger circle), were highly correlated (party: $r(2697)=.90, p<.001$; candidate: $r(2697)=.89, p<.001)$, we aggregated the distance and overlap measures for analysis, retaining independent measures of candidate versus party fusion. In line with previous research (e.g., Newson et al., 2009), correlations between identity fusion and self-reported measures of party identification and candidate support were positive and of large magnitude $(r(2694)=.64, p<.001$ and $r(2697)=.66, p<.001$, respectively). 


\section{Event Evaluation}

Before the election, supporters of both candidates indicated that they would be much happier about the victory of their preferred candidate compared to the victory of their rival (Democrats:

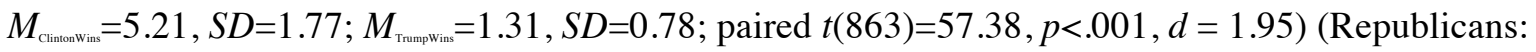
$M_{\text {Trumpwim }}=5.40, S D=1.72 ; M_{\text {climanxim }}=1.36, S D=0.82$; paired $\left.t(449)=43.13, p<.001, d=2.03\right)$. After the election, Democrats reported much less happiness about the outcome than Republicans $\left(M_{\mathrm{D} \mathrm{m}}=1.91\right.$, $S D=1.25 ; M_{\mathrm{Rep}}=5.67, S D=1.43$; Welch's $\left.t(926.4)=48.30, p<.001, d=2.84\right)$. Thus, consistent with previous research (Pierce et al., 2016), as well as with partisans' pre-election predictions, the election was indeed impactful and emotionally salient for participants.

\section{Question One: Dynamics of Identity Fusion}

\section{Identity Fusion Before versus After the Election}

To investigate the event shock (election outcome: losing for Democrats and winning for Republicans), we analyzed data via linear models predicting identity fusion as a function of party preference and time point (dummy coded as before versus after the election), retaining terms where significant or where figuring in a higher-order interaction. We present results separately for fusion with the party and fusion with supporters of the candidate.

Partisans' average identity fusion with their party before the election was $M_{\mathrm{Dem}}=41.42$ $(S D=40.52)$ and $M_{\mathrm{Rep}}=37.52(S D=42.90)$; after the election, it was $M_{\mathrm{Dem}}=45.95(S D=39.10)$ and $M_{\mathrm{Re}}=45.06(S D=39.87)$. The interaction between party identity and time point was not significant $(\beta=3.02, \mathrm{t}(2695)=.93, p=.35)$ and was therefore dropped. The main effect of party identity was also not significant $(\beta=-2.36, \mathrm{t}(2696)=-1.62, p=.14)$, leaving only time point (pre- versus post-election) in the model, $(\beta=5.54, \mathrm{t}(2696)=3.57, p<.001, R=.005)$.

Partisans' average identity fusion with the supporters of their candidate was $M_{\mathrm{Dm}}=34.01$ $(S D=43.38)$ and $M_{\mathrm{Rep}}=40.60(S D=46.61)$; after the election, it was $M_{\mathrm{Dem}}=38.60(S D=40.90)$ and $M_{\mathrm{Rep}}=46.47(S D=42.80)$. The interaction between candidate preference and time point was not significant $(\beta=1.28, \mathrm{t}(2695)=.37, p=.71)$ and was once again dropped. Identity fusion with the group of candidate supporters was significantly predicted by time point $(\beta=5.05, \mathrm{t}(2696)=3.04, p=.002$, 
$\eta=.003)$. There was also a significant effect of candidate preference $(\beta=7.24, \mathrm{t}(2696)=4.18, p<.001$, $\eta=.006$ ), with Trump supporters showing, on average, greater fusion with other supporters of their candidate.

Thus, the election itself was associated with an increase in identity fusion with both party and candidate supporters in both Democrats, who experienced a negative shock, and Republicans, who experienced a positive shock. Supporters of Trump were somewhat more fused with other candidate supporters than were supporters of Clinton. However, the hypothesis that losing would be associated with a larger shift in identity fusion was not supported at either the party or candidate level. Further, the magnitude of change was quite small, never exceeding $1 \%$ of observed variance.

\section{Continuous Change in Identity Fusion over the Study Period}

The preceding analyses explored the role of a single event, the election, asking how it affected identity fusion. However, that analysis collapses 5 pre-election and 5 post-election data collection waves, such that the results could also be explained by a gradual shift over the study period. To explore this alternative possibility, we analyzed identity fusion in a more fine-grained manner, including a measure of time in our analyses, coded as data collection waves 1 through 10 . To account for the possibility that the trend in wave-related change might differ pre- to post-election, we retained the dichotomous predictor of time point utilized above, as well as the main effect of participant party (Democrat or Republican) and all interaction terms. Broadly speaking, this analysis allows the slope of the estimate associated with wave to differ before versus after the election and for Republicans versus Democrats.

Beginning with the analysis focusing on party fusion, there was a main effect of wave, $(\beta=2.12, \mathrm{t}(2695)=2.74, p=.006, \eta=.001$ and a marginal main effect of pre/post-election, $(\beta=11.69$, $\left.\mathrm{t}(2695)=1.72, p=.085, \eta^{2}<.001\right)$; however, these main effects were qualified by a marginal interaction between wave and pre/post $\left(\beta=-2.09, \mathrm{t}(2695)=-1.91, p=.056, \eta^{2}=.001\right)$. No terms including participant party reached significance. Thus, the positive effect of wave pre-election diminished to near 0 after the election. These patterns were confirmed by analyzing the effect of wave separately in the preelection $(\beta=2.13, \mathrm{t}(1343)=2.68, p=.0075, R=.005)$ and post-election $(\beta=.03, \mathrm{t}(1352)=.05, p=.96)$ 
periods. Identity fusion grew stronger up to the election but then leveled off after the election; this pattern was similar for Republicans and Democrats (Figure 1, left panel).

Turning to fusion with supporters of one's preferred candidate, the analysis paralleling that described above produced a significant three-way interaction between party, pre/post-election, and wave $(\beta=4.80, \mathrm{t}(2691)=2.43, p=.048, R=.016)$. To unpack this interaction, we next fit separate models examining the pre- versus post-election period. Beginning with the pre-election period, this analysis revealed a significant positive main effect of wave $(\beta=2.80, \mathrm{t}(1342)=3.28, p=.001, \eta=.008)$ as well as a significant and positive effect of party, with greater fusion in Trump supporters $(\beta=6.37$, $\left.\mathrm{t}(1342)=2.50, p=.012, \eta^{2}=.004\right)$. Thus, pre-election Trump supporters were more fused with Trump supporters overall, and fusion tended to be higher for both Clinton supporters and Trump supporters as the election approached. In the post-election period, this analysis suggested that fusion continued to trend upward for Trump supporters but not for Clinton supporters. The main effect of wave, corresponding to the effect for Clinton supporters, did not differ from $0,(\beta=-.48, \mathrm{t}(1350)=-.48$, $p=.63$ ), but the interaction between wave and party, corresponding to the increased effect of wave for Trump supporters, was marginal $\left(\beta=2.91, \mathrm{t}(1350)=1.77, p=.078, R^{2}=.01\right)$. No other effects approached significance. Thus, fusion with supporters of the same candidate trended upwards leading up to the election, then appeared to level off for Clinton supporters while continuing to trend upwards for Trump supporters (Figure 1, right panel).

More generally, these analyses suggest that, in the run-up to the election, fusion tended to be greater as the election neared; in the post-election period, the picture was more complex, generally involving a plateau in fusion, except for the case of Trump supporters' fusion with fellow Trump supporters, which continued to increase over the remainder of the study period. Thus, while we did find evidence for changes in fusion with both party and candidate supporters over the study period, these changes did not appear to be best explained by a salient "identity shock" as much as a gradual shift in the direction of greater fusion up to the election. The only hint of evidence for a differential effect of the election on winners versus losers was the finding (albeit based on a marginal interaction) 
that Trump supporters' fusion with other Trump supporters continued to trend upwards after the election while that trend was absent for Clinton supporters.
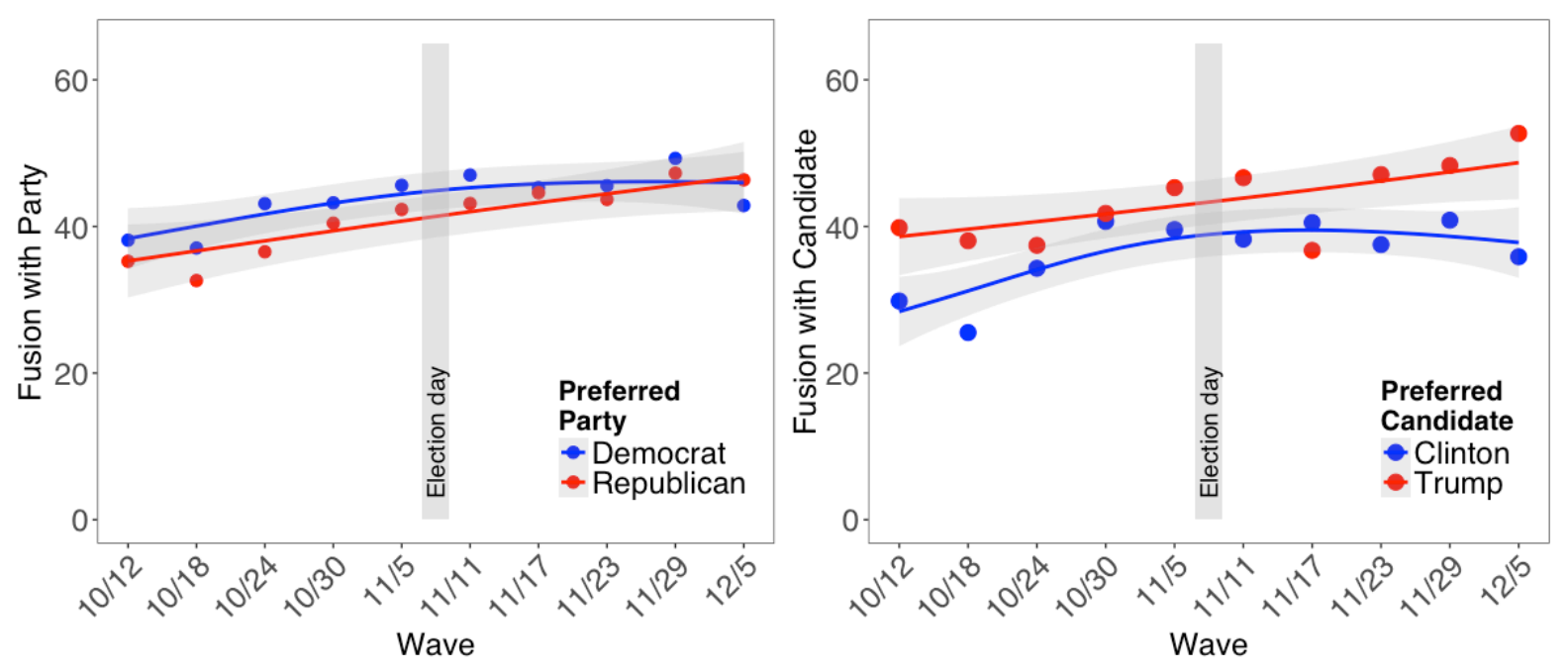

Figure 1. Identity fusion (and 95\% confidence bands with GAM smoothing) as a function of data collection wave for Democrats and Republicans. Left panel displays fusion with party and right panel displays fusion with supporters of the favored candidate.

\section{Impact of Previous Commitment on Identity Fusion}

Previous research suggests that the dynamics of identity fusion might differ between strongly versus weakly identified individuals (Vázquez et al., 2016). Because we tested a sample of distinct participants for each wave, we could not directly assess individual participants' change in identity fusion over time. However, we assessed other self-reported behavioral measures that are indicative of previous commitment. At the party level, these indicators were (1) prior party membership, (2) selfreported, party-directed donations in the past, and (3) self-reported, party-directed volunteering in the past. At the candidate level, these indicators were (1) candidate support in the primary election and (2) candidate-directed donations and (3) candidate-directed volunteering. To factor these prior commitments in, we created two previous commitment scores, one for preferred party and one for preferred candidate, calculated as the sum of the number of "yes" responses to each of the three indicators; that is, we created a composite ranging from 0 to 3 to indicate how many prior commitments were present (e.g. a partisan who volunteered for Trump and voted for him in the 
primary, but did not donate money, would receive a prior commitment score of 2 out of a possible 3). To investigate whether including these factors would allow us to pick up on a potential identity shock related to the election outcome, we fit additional linear regressions predicting fusion but including our new previous commitment score, described above, in addition to time point (pre- versus post-election) and participants' preferred party and candidate.

Beginning with party fusion, this model again confirmed that fusion was higher after the election $\left(\beta=9.17, \mathrm{t}(2694)=3.96, p<.001, \eta^{2}=.004\right)$, but again no effect of participant party was found $(\beta=-0.04, \mathrm{t}(2694)=-0.25, p=.98)$. We found a significant and large effect of previous party commitment $\left(\beta=18.73, \mathrm{t}(2694)=14.92, p<.001, \eta^{2}=.12\right)$, indicating that previously committed partisans showed higher levels of fusion. Furthermore, we found an interaction between previous party commitment and time point $(\beta=-3.88, \mathrm{t}(2694)=-2.21, p=.027, \eta=.002)$, suggesting that, after the election, previous commitment was less predictive of identity fusion.

Turning to fusion with the supporters of the candidate, in a model including previous candidate-related commitment, we again found a main effect of time point (pre- versus post-election) $\left(\beta=5.60, \mathrm{t}(2694)=2.40, p<.001, \eta^{2}=.004\right)$ and a large effect of prior commitment $(\beta=19.80$, $\mathrm{t}(2694)=14.30, p<.001, \eta=.12)$ but no effect of preferred candidate $(\beta=0.48, \mathrm{t}(2694)=0.22, p=.83)$.

However, we found a positive interaction between prior commitment and candidate preference $\left(\beta=4.91, \mathrm{t}(2694)=2.08, p=.038, \eta^{2}=.001\right)$, with previous commitment predicting fusion more powerfully in Trump supporters. Thus, previous commitment was again predictive of identity fusion.

Overall, while revealing some additional nuances, these analyses dovetail with the primary analyses presented above to suggest that the effect of the election and election period did not differ among supporters of the winning versus losing candidate, though Trump supporters who had engaged in prior commitment behaviors were particularly fused with other supporters of that candidate.

\section{Question Two: Effect of Identity F usion on Participants' Ingroup Giving} Impact of Fusion on Giving

At the end of the survey, participants were promised a bonus of 40 cents and asked to indicate how much of this bonus they would want to give to another participant who shared their preferences 
regarding political party and presidential candidate. Of this 40 -cent bonus, participants donated, on average, 13.38 cents $(S D=10.96)$, or $34 \%$, to their ingroup members.

To investigate the effect of identity fusion on ingroup giving, we ran a linear model including identity fusion, party preference and time point (pre/post) ${ }^{2}$. To identify whether identity fusion with the party or with supporters of the preferred candidate was a better predictor for ingroup giving, we included both DIFI measures (mean-centered) in the same model. This model revealed multiple significant effects. First, there was a main effect of time point (pre/post), with greater amounts of giving occurring after the election $(\beta=1.29, \mathrm{t}(2646)=3.09, p=.002, \eta=.004)$. There was a significant effect of fusion with candidate supporters $\left(\beta=.053, \mathrm{t}(2646)=4.60, p<.001, \eta^{2}=.004\right)$, but not with party $(\beta=.012, \mathrm{t}(2646)=1.08, p=.28)$. These effects were qualified by several interactions. First, the effect of fusion with candidate supporters was both weaker after the election (time point $\mathrm{x}$ candidate supporters fusion interaction: $\left.\beta=-.027, \mathrm{t}(2645)=-2.76, p=.006, \eta^{2}=.003\right)$ and weaker, generally, in Republicans (candidate supporters fusion x party interaction: $\beta=-.036, \mathrm{t}(2645)=-2.41, p=.016, \eta^{2}=$ $.002)$. Finally, there was a three-way interaction between both fusion measures and party $(\beta=-.0005$, $\left.\mathrm{t}(2644)=-2.22, p=.027, \eta^{2}=.002\right)$, indicating that Trump supporters that were high on both fusion measures gave somewhat less than would otherwise have been predicted. The predicted effects of fusion with candidate supporters and party fusion as predictors of dictator game giving are plotted in Figure 2.

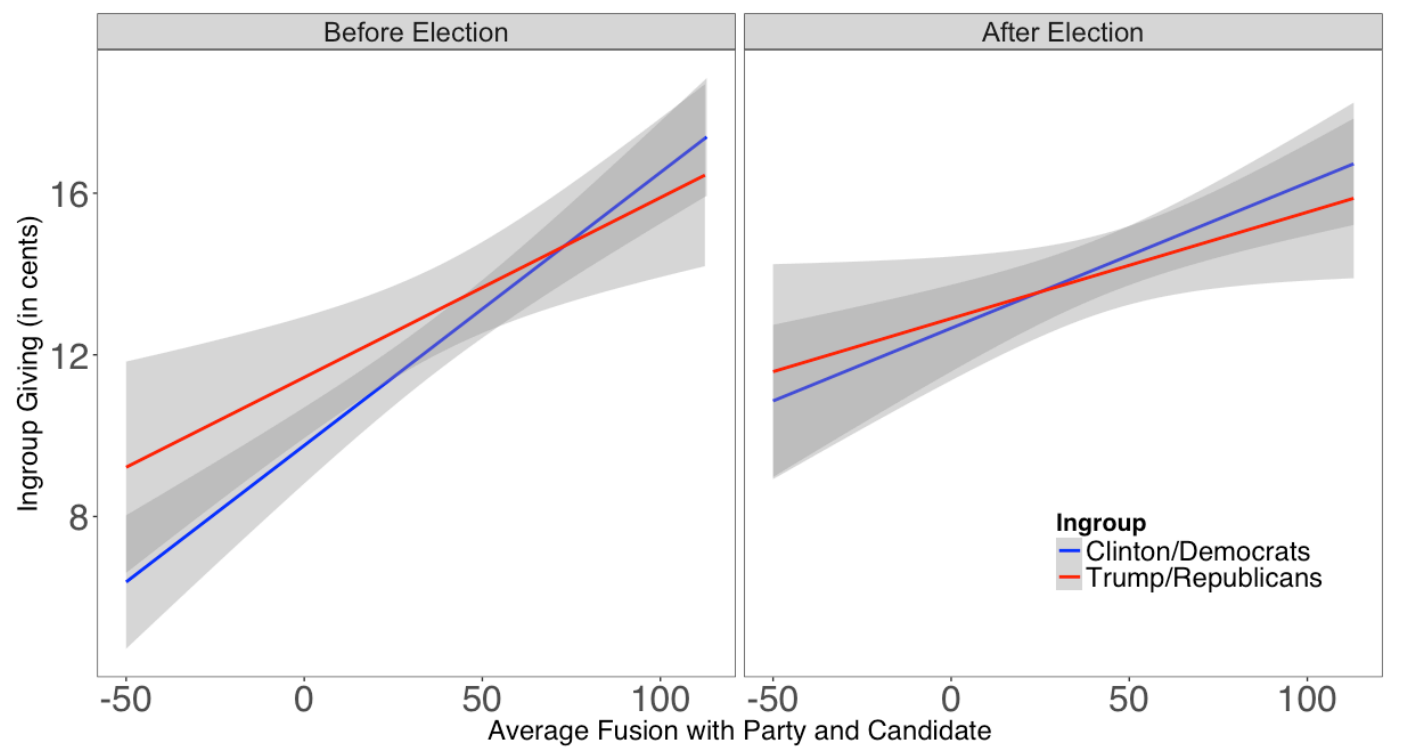


Figure 2. Ingroup giving (with $95 \%$ confidence bands) in the dictator game as a function of identity fusion. For simplicity of presentation, we plot average fusion scores for both party and candidate supporters before (left panel) and after (right panel) the election.

\section{Impact of Previous Commitment on Giving}

Does identity fusion remain a potent predictor of ingroup giving when other measures of commitment are included in the model? To explore this question, we built on the model described above by including the explicit measures of candidate and party support as well as the measures of behavioral commitment described above. However, when added to the final model described above, none of the terms associated with party identification, candidate support, commitment behaviors to party, or commitment behaviors to candidate reached significance, all $t(2639)<1.66, p>.096$. Thus, once identity fusion was accounted for, these other indicators of commitment to party and candidate did not meaningfully relate to ingroup giving.

\section{Discussion}

The current study examined the dynamics of identity fusion and the conditions that foster a deep emotional connection between group members during times of group-related tumult. It did so by investigating the effect of salient negative and positive group events on group members' identity fusion with their political group in the context of the 2016 U.S. national election. It also investigated the consequences of identity fusion - namely, whether levels of identity fusion were predictive of prosocial ingroup behavior. In this discussion, we briefly review our primary findings before turning to the more general implications and limitations of this work.

Our primary hypothesis was that identity fusion would increase in supporters of the losing party as a consequence of the negative event. This hypothesis was not supported. Instead, we found that, while fusion was generally higher after the election, the temporal dynamics were more consistent with a gradual increase throughout the period leading up to the election rather than a sudden jump after the election. These dynamics were similar for both parties, though there was some evidence that 
identity fusion was higher in supporters of Trump generally, and that the wave-related increase in fusion that characterized the pre-election period continued in the post-election period for Trump supporters' fusion with other supporters of Trump.

While a defeat in a national election is unlikely to be comparable to the painful, shared, and dysphoric experiences discussed by Whitehouse and colleagues (2017), losing the election was emotionally impactful for the participants, as indicated by the dramatic difference in happiness ratings in supporters of the defeated versus victorious party. Several studies have provided support for the notion that identity fusion with a group increases after negative experiences (Jong et al., 2015; Mancini et al., 2015; Vezzali et al., 2015; Whitehouse et al., 2014), but results of our study suggest that, at least when it comes to less extreme contexts, the valence of the event does not necessarily influence the dynamics of identity fusion differently. This is in line with previous correlational research suggesting that both euphoric and dysphoric events are associated with increases in identity fusion (Newson et al., 2016), group cohesion (Evans \& Dion, 1991; Mullen \& Cooper, 1994), and interpersonal closeness (Boothby, Clark, \& Bargh, 2014).

Our second hypothesis was that identity fusion would predict costly ingroup giving, and would do so better than other commonly used measures. Our data clearly support this: We found that identity fusion was a better predictor of prosocial ingroup giving than previous commitment, party identification, or candidate support. Further, by having participants choose whether to donate a portion of an actual monetary bonus (rather than asking them to merely report their willingness to engage in prosocial ingroup behavior), we assessed real and individually costly pro-group behavior. Thus, we add to a growing body of evidence that identity fusion predicts actual behavior, and does so to a greater extent than comparable self-reported measures like social identification (e.g., Bastian et al., 2014; Buhrmester et al., 2015; Gómez et al., 2011; Swann, Gómez, Huici, et al., 2010). Interestingly, we found that the relationship between identity fusion and prosocial ingroup giving weakened in the weeks after the event, even though both fusion and giving were higher overall after the election. Previous accounts propose that identity fusion fosters prosocial ingroup behavior so that people can come together and fight for their group, especially in times of extreme need 
(Whitehouse et al., 2017). At first glance, our results may seem in tension with this notion, both because the effect on identity fusion on prosocial giving was the same for both winners and losers of the election and because the effect decreased after the election. However, we suspect that this divergence from past predictions may stem from the unique characteristics of a national election, which differs from some of the previously studied group events. In the majority of previously discussed events, such as terror attacks, wars, or natural disasters, pro-group action is most essential in the aftermath of the event as a means of mobilizing against the enemy or helping to rebuild society. In contrast, in the case of an election, it is the time before the event in which relevant political groups are in greater need of support and in which an individual's prosocial behavior is likely to have the most concrete impact. Our findings suggest that identity fusion fosters prosocial group behavior most powerfully when the behavior in question is or feels potentially impactful in terms of supporting the group. This factor may be more causally central than timing per se-a hypothesis that could fruitfully be explored in lab-based work, wherein the nature and timing of the impactful event could be experimentally manipulated.

Our focus on a salient, real-world event is a strength of our study, but, as with any such work, it would be unwise to generalize too freely from our findings. First, because we were not able to survey the same participants over the course of the study, our results are susceptible to idiosyncratic differences between samples, which we tried to counteract by testing a large number of participants, but which should still be kept in mind. Second, the 2016 U.S. Presidential Election was unusual in several ways. To name just a few, it featured two relatively unpopular candidates, one of whom emerged from outside the political mainstream; it energized segments of the electorate that may not have previously been politically engaged; and it was characterized by unusual acrimony, even for a U.S. national election. Whether our results would generalize to another U.S. Presidential Election - or to other social contests - is unclear. In this regard, it is also important to note that our design asked all participants to indicate a preference for one of the two major party candidates, rather than for any party candidate whatsoever. Not including those who favored a third-party candidate could have weakened the observed patterns. However, participants did have options to indicate a distance 
between themselves from their preferred major party candidate via the Likert scales and DIFI measure used throughout the survey. Further, all discussions of the effects of the election on "winners" versus "losers" are inescapably confounded with other factors, most notably that winners were always Republican Trump supporters while losers were always Democratic Clinton supporters; these groups likely differ along multiple dimensions. However, understanding the dynamics of identity fusion requires engaging with this complexity and mining it for hypotheses that can be tested in more controlled settings. In the present context, we conclude by highlighting three topics as most relevant for motivating future work.

First, in the context of a national election - a less extreme but still consequential event - we observed gradual increases in identity fusion rather than a dramatic shift around the event's resolution. This departure from the predictions of an "identity shock" model may occur because of the extremely high salience of the election both before and after its resolution, which plausibly makes the election itself only one part of a larger unfolding event. In this sense, the "event" of an election may not be best conceptualized as a single day so much as an extended season. Extending data collection to an even wider window (e.g., beginning before the more fevered parts of campaign) could shed light on this possibility.

Second, contrary to our prediction that a losing event would lead to a larger increase in identity fusion, we observed equivalent increases in fusion in both parties leading up to the event, but no differential increase in winning Republicans and losing Democrats after the event. The only notable finding was that the increase of identity fusion with Trump supporters continued to trend upwards after the election. While this finding seems to contradict our hypothesis, it is based on marginal results and thus should be interpreted with caution. It is possible that events like national elections present a richer set of social dynamics, such that they provide abundant motivations for fusion in both groups; it is also possible that particular features of this election, such as the widespread expectation that Clinton would win, changed the way in which partisans responded to the outcome. Exploring expectations could be an interesting avenue for future work: for example, one reason why negative events sometimes promote greater fusion is that such events are usually 
unexpected. Are unexpected positive events (e.g., Trump's victory in the eyes of his supporters) thereby more impactful? Relatedly, it remains open how partisans' personal evaluation of the event and its subjective impact on their personal and group life might have influenced the dynamics of identity fusion on an individual level, which is an interesting avenue for future research.

Third, our results provide further support for the power of identity fusion as a predictor of real and costly prosocial behavior. However, the differential relationship between fusion and behavior before versus after the election is, to our knowledge, a novel finding. Past work has generally argued that experiencing an identity shock increases prosocial behavior. Our findings suggest an additional nuance, namely that the relationship between fusion and behavior may also stem from the individual's appraisal that their behavior will support group cohesion at a critical time. In the context of, e.g., a natural disaster, the critical time is clearly during the disaster's aftermath, but in the context of an election, the critical time is more plausibly before the election date. The role of such felt efficacy is an interesting avenue for future follow-up in this area.

In conclusion, our work provides a window into the unfolding dynamics of identity fusion, prosocial behavior, and group identification in the broader context of a salient and high-stakes national event. We find that fusion generally increased in the weeks leading up to the event, but that there was no a greater increase in fusion in those who experienced the more negative outcome. We also find that identity fusion is an important predictor of group-directed prosocial behavior, out performing other measures of identification, especially during the period in which such behavior plausibly best serves the group's ends, namely the period running up to the resolution of a heated political contest. 


\section{PARTISANS’ IDENTITY FUSION 21}

\section{Notes}

1. Another approach to investigating this question would be to fit a non-linear model, for example by including polynomial terms. However, with only 10 values for $\mathrm{x}$ (corresponding to our 10 time points), our ability to do so was limited. We opted for this interactive approach instead.

2. Some researchers have suggested that the Dictator Game should be modeled as censored data (Engel, 2011) on the rationale that the underlying preferences of some individuals would motivate them to take money away from their partner if that were possible (creating hypothetical negative values) or to give beyond their endowment if that were possible (creating hypothetical values above 40 -cents). This implies that our data is left-censored at 0 and right-censored at 40 cents, and that a tobit model accounting for censoring would be appropriate. We re-ran our final models as left and right censored tobit models using the censReg package in R (Henningsen, 2017). This produced substantively identical conclusions though in the final model predicting giving via both fusion measures, time point, and party preferences, the 3-way interaction between the fusion measures and party preference was only marginally significant in the tobit model $(p=.081$, as compared to .027 in the linear model). 
PARTISANS’ IDENTITY FUSION 22

\section{References}

Atran, S., Sheikh, H., \& Gomez, A. (2014). Devoted actors sacrifice for close comrades and sacred cause. Proceedings of the National Academy of Sciences, 111(50), 17702-17703. doi: $10.1073 /$ pnas.1420474111

Barker, D. C., Lawrence, A. B., \& Tavits, M. (2006). Partisanship and the dynamics of "candidate centered politics" in American presidential nominations. Electoral Studies, 25(3), 599-610.

Bastian, B., Jetten, J., \& Ferris, L. J. (2014). Pain as social glue: Shared pain increases cooperation. Psychological Science, 25(11), 2079-2085.

Besta, T., Gómez, Á., \& Vázquez, A. (2014). Readiness to deny group’s wrongdoing and willingness to fight for its members: the role of Poles' identity fusion with the country and religious group. Current Issues in Personality Psychology, 1, 49-55. doi: 10.5114/cipp.2014.43101

Blanton, H., Strauts, E., \& Perez, M. (2012). Partisan identification as a predictor of cortisol response to election news. Political Communication, 29(4), 447-460.

Boothby, E. J., Clark, M. S., \& Bargh, J. A. (2014). Shared experiences are amplified. Psychological Science, 25(12), 2209-2216. doi: 10.1177/0956797614551162

Buhrmester, M. D., Fraser, W. T., Lanman, J. A., Whitehouse, H., \& Swann, W. B. (2015). When terror hits home: identity fused Americans who saw Boston bombing victims as "family" provided aid. Self and Identity, 14(3), 253-270. doi: 10.1080/15298868.2014.992465

Buhrmester, M. D., Gómez, Á., Brooks, M. L., Morales, J. F., Fernández, S., \& Swann, W. B. (2012). My group's fate is my fate: Identity-fused Americans and Spaniards link personal life quality to outcome of 2008 elections. Basic and Applied Social Psychology, 34(6), 527-533.

Enten, H. (2016, May 5). Americans' distaste for both Trump and Clinton is record-breaking. Retrieved August 23, 2017, from https://fivethirtyeight.com/features/americans-distaste-forboth-trump-and-clinton-is-record-breaking/

Evans, C. R., \& Dion, K. L. (1991). Group cohesion and performance: A meta-analysis. Small Group Research,22(2), 175-186. 
Forsythe, R., Horowitz, J. L., Savin, N. E., \& Sefton, M. (1994). Fairness in simple bargaining experiments. Games and Economic Behavior, 6(3), 347-369.

Franzen, A., \& Pointner, S. (2013). The external validity of giving in the dictator game. Experimental Economics, 16(2), 155-169.

Fredman, L. A., Buhrmester, M. D., Gomez, A., Fraser, W. T., Talaifar, S., Brannon, S. M., \& Swann, W. B. (2015). Identity fusion, extreme pro-group behavior, and the path to defusion. Social and Personality Psychology Compass, 9(9), 468-480. doi: 10.1111/spc3.12193

Gómez, Á., Brooks, M. L., Buhrmester, M. D., Vázquez, A., Jetten, J., \& Swann, W. B. (2011). On the nature of identity fusion: Insights into the construct and a new measure. Journal of Personality and Social Psychology, 100(5), 918-933. doi: 10.1037/a0022642

Gómez, Á., Morales, J. F., Hart, S., Vázquez, A., \& Swann, W. B. (2011). Rejected and excluded forevermore, but even more devoted: irrevocable ostracism intensifies loyalty to the group among identity-fused persons. Personality and Social Psychology Bulletin, 37(12), 15741586. doi: $10.1177 / 0146167211424580$

Hamilton, W. D. (1964). The genetical evolution of social behaviour. II. Journal of Theoretical Biology, 7(1), 17-52. doi: 10.1016/0022-5193(64)90039-6

Henningsen, Arne (2017). censReg: Censored Regression (Tobit) Models. R package version 0.5. http://CRAN.R-Project.org/package=censReg

Henrich, J. (2004). Cultural group selection, coevolutionary processes and large-scale cooperation. Journal of Economic Behavior \& Organization, 53(1), 3-35. doi: 10.1016/S01672681(03)00094-5

Jiménez, J., Gómez, Á., Buhrmester, M. D., Vázquez, A., Whitehouse, H., \& Swann, W. B. (2016). The Dynamic Identity Fusion Index: a new continuous measure of identity fusion for webbased questionnaires. Social Science Computer Review, 34(2), 215-228. doi: $10.1177 / 0894439314566178$ 
Jong, J., Whitehouse, H., Kavanagh, C., \& Lane, J. (2015). Shared negative experiences lead to identity fusion via personal reflection. PLOS ONE, 10(12), e0145611. doi: 10.1371/journal.pone.0145611

Kahneman, D., Knetsch, J. L., \& Thaler, R. H. (1986). Fairness and the assumptions of economics. Journal of Business, S285-S300.

Kludt, T. (2016, September 12). Pew poll: Most voters "frustrated," "disgusted” with 2016 election. CNN. Retrieved from http://www.cnn.com/2016/09/21/politics/pew-poll-hillary-clintondonald-trump/index.html

Mancini, A. D., Littleton, H. L., \& Grills, A. E. (2015). Can people benefit from acute stress? Social support, psychological improvement, and resilience after the Virginia Tech Campus shootings. Clinical Psychological Science, 2167702615601001. doi:

$10.1177 / 2167702615601001$

Mullen, B., \& Copper, C. (1994). The relation between group cohesiveness and performance: An integration. Psychological Bulletin, 115(2), 210-227. doi: 10.1037/0033-2909.115.2.210

Newson, M., Buhrmester, M., \& Whitehouse, H. (2016). Explaining lifelong loyalty: The role of identity fusion and self-shaping group events. PLOS ONE, 11(8), e0160427. doi: 10.1371/journal.pone. 0160427

Nowak, M. A. (2006). Five rules for the evolution of cooperation. Science, 314(5805), 1560-1563. doi: $10.2307 / 20032978$

Pierce, L., Rogers, T., \& Snyder, J. A. (2016). Losing hurts: The happiness impact of partisan electoral loss. Journal of Experimental Political Science, 3(01), 44-59. doi: 10.1017/XPS.2015.8

Rapoport, R. B. (1997). Partisanship change in a candidate-centered era. The Journal of Politics, 59(1), 185-199.

Simpson, J. A., \& Beckes, L. (2010). Evolutionary perspectives on prosocial behavior. In M. Mikulincer \& P. R. Shaver (Eds.), Prosocial motives, emotions, and behavior: The better angels of our nature. (pp. 35-53). Washington: American Psychological Association. 
Swann, W. B., \& Buhrmester, M. D. (2015). Identity fusion. Current Directions in Psychological Science, 24(1), 52-57.

Swann, W. B., Gómez, Á., Buhrmester, M. D., López-Rodríguez, L., Jiménez, J., \& Vázquez, A. (2014). Contemplating the ultimate sacrifice: Identity fusion channels pro-group affect, cognition, and moral decision making. Journal of Personality and Social Psychology, 106(5), 713-727. doi: 10.1037/a0035809

Swann, W. B., Gomez, A., Dovidio, J. F., Hart, S., \& Jetten, J. (2010). Dying and killing for one's group: Identity fusion moderates responses to intergroup versions of the trolley problem. Psychological Science, 21(8), 1176-1183. doi: 10.1177/0956797610376656

Swann, W. B., Gómez, Á., Huici, C., Morales, J. F., \& Hixon, J. G. (2010). Identity fusion and selfsacrifice: Arousal as a catalys of pro-group fighting, dying, and helping behavior, 99(5), 824841.

Swann, W. B., Gómez, Á., Seyle, D. C., Morales, J. F., \& Huici, C. (2009). Identity fusion: The interplay of personal and social identities in extreme group behavior. Journal of Personality and Social Psychology, 96(5), 995-1011. doi: 10.1037/a0013668

Swann, W. B., Jetten, J., Gómez, Á., Whitehouse, H., \& Bastian, B. (2012). When group membership gets personal: A theory of identity fusion. Psychological Review, 119(3), 441-456. doi: $10.1037 / \mathrm{a} 0028589$

Tajfel, H., \& Turner, J. C. (2004). The social identity theory of intergroup behavior. In J. T. Jost \& J. Sidanius (Eds.), Key readings in social psychology (pp. 276-293). New York: Psychology Press.

Vázquez, A., Gómez, Á., Ordoñana, J. R., Swann, W. B., \& Whitehouse, H. (2017). Sharing genes fosters identity fusion and altruism. Self and Identity, $O(0), 1-19$. doi: $10.1080 / 15298868.2017 .1296887$

Vázquez, A., Gómez, Á., \& Swann, W. B. (2017). Do historic threats to the group diminish identity fusion and its correlates? Self and Identity, 16(4), 480-503. 
Vezzali, L., Drury, J., Versari, A., \& Cadamuro, A. (2016). Sharing distress increases helping and contact intentions via social identification and inclusion of the other in the self: Children's prosocial behaviour after an earthquake. Group Processes \& Intergroup Relations, 19(3), 314-327.

Wattenberg, M. P. (1987). The hollow realignment partisan change in a candidate-centered era. Public Opinion Quarterly, 51(1), 58-74.

Whitehouse, H. (2012). Ritual, Cognition, and Evolution. In R. Sun (Ed.), Grounding social sciences in cognitive sciences (pp. 265-84). MIT Press.

Whitehouse, H., Jong, J., Buhrmester, M. D., Gómez, Á., Bastian, B., Kavanagh, C. M., ... Gavrilets, S. (2017). The evolution of extreme cooperation via shared dysphoric experiences. Scientific Reports, 7, srep44292. doi: 10.1038/srep44292

Whitehouse, H., \& Lanman, J. A. (2014). The ties that bind us: Ritual, fusion, and identification. Current Anthropology, 55(6), 674-695. doi: 10.1086/678698

Whitehouse, H., \& McQuinn, B. (2013). Ritual and violence: Divergent modes of religiosity and armed struggle. In M. Jerryson, M. Juergensmeyer, \& M. Kitts (Eds.), The Oxford Handbook of Religion and Violence. Oxford: Oxford University Press.

Whitehouse, H., McQuinn, B., Buhrmester, M., \& Swann, W. B. (2014). Brothers in arms: Libyan revolutionaries bond like family. Proceedings of the National Academy of Sciences, 111(50), 17783-17785. doi: 10.1073/pnas.1416284111 
Appendix

\section{Question One: Dynamics of Identity Fusion}

Identity Fusion Before versus After the Election

Table 1

Coefficients of the linear model predicting identity fusion with political party as a function of party preference and time point.

\begin{tabular}{lcccc}
\hline & Estimate & Std. Error & $t$ & $p$ \\
\hline Intercept & 40.074 & 1.101 & 36.389 & $<.001$ \\
Time Point (post) & 5.544 & 1.555 & 3.565 & $<.001$ \\
\hline
\end{tabular}

Table 2

Coefficients of the linear model predicting identity fusion with supporters of the candidate as a function of party preference and time point.

\begin{tabular}{lcccc}
\hline & Estimate & Std. Error & $t$ & $p$ \\
\hline Intercept & 33.785 & 1.318 & 25.64 & $<.001$ \\
Time Point (post) & 5.047 & 1.659 & 3.042 & .002 \\
Party Preference & & & & \\
(Republican) & 7.239 & 1.73 & 4.184 & $<.001$ \\
\hline
\end{tabular}

Table 3

Coefficients of linear model predicting identity fusion with political party as a function of party preference, time point, and wave.

\begin{tabular}{lcccc}
\hline & Estimate & Std. Error & $t$ & $p$ \\
\hline Intercept & 33.66 & 2.589 & 13.002 & $<.001$
\end{tabular}


PARTISANS' IDENTITY FUSION 28

Wave

2.126

0.776

2.740

0.062

Time Point (post)

11.691

6.782

1.724

0.085

Wave : Time Point

$-2.092$

1.093

$-1.913$

0.056

Table 4

Coefficients of linear model predicting identity fusion with political party as a function of wave before the election.

\begin{tabular}{lcccc}
\hline & Estimate & Std. Error & $t$ & $p$ \\
\hline Intercept & 33.66 & 2.589 & 13.002 & $<.001$ \\
Wave & 2.126 & 0.776 & 2.740 & 0.006 \\
\hline
\end{tabular}

Table 5

Coefficients of linear model predicting identity fusion with political party as a function of wave after the election

\begin{tabular}{lcccc}
\hline & Estimate & Std. Error & $t$ & $p$ \\
\hline Intercept & 45.346 & 6.120 & 17.409 & $<.001$ \\
Wave & .034 & 0.752 & .045 & .964 \\
\hline
\end{tabular}

Table 6

Coefficients of linear model predicting identity fusion with supporters of the candidate as a function of candidate preference, time point, and wave.

\begin{tabular}{lcccc}
\hline & Estimate & Std. Error & $t$ & $p$ \\
\hline Intercept & 23.648 & 3.394 & 6.968 & $<.001$ \\
Wave & 3.462 & 1.025 & 3.376 & $<.001$
\end{tabular}


PARTISANS' IDENTITY FUSION 29

Time Point (post)

18.740

9.034

2.074

.038

Party Preference (Republican)

12.131

5.826

2.082

.037

Wave : Time Point

$-3.937$

1.456

$-2.705$

.007

Wave : Party Preference

$-1.892$

1.735

$-1.091$

.275

Time point : Party Preference

$-27.685$

15.068

$-1.837$

.066

Wave : Time point : Party

Preference

4.800

2.431

1.975

.048

Table 7

Coefficients of linear model predicting identity fusion with supporters of candidate as a function of wave before the election.

\begin{tabular}{lcccc}
\hline & Estimate & Std. Error & $t$ & $p$ \\
\hline Intercept & 25.626 & 2.959 & 8.659 & $<.001$ \\
Wave & 2.801 & 0.853 & 3.282 & .001 \\
Candidate Preference (Trump) & 6.373 & 2.545 & 2.504 & .012 \\
\hline
\end{tabular}

Table 8

Coefficients of linear model predicting identity fusion with supporters of the candidate as a function of wave after the election.

\begin{tabular}{lcccc}
\hline & Estimate & Std. Error & $t$ & $p$ \\
\hline Intercept & 42.388 & 8.099 & 5.234 & $<.001$ \\
Wave & -.475 & 1.000 & -.475 & .635 \\
Candidate Preference (Trump) & -15.554 & 13.444 & -1.157 & .248 \\
Wave : Party Preference & 2.908 & 1.648 & 1.765 & .078 \\
\end{tabular}




\section{Impact of Previous Commitment on Identity Fusion}

Table 9

Coefficients of linear model predicting identity fusion with political party as a function of time point, party preference, and previous commitment to the party.

\begin{tabular}{lcccc}
\hline & Estimate & Std. Error & $t$ & $p$ \\
\hline Intercept & 21.134 & 1.750 & 12.081 & $<.001$ \\
Time Point (post) & 9.168 & 2.314 & 3.961 & $<.001$ \\
Party Preference (Republican) & -.038 & 1.527 & -.025 & .980 \\
Previous Commitment & 18.725 & 1.255 & 14.922 & $<.001$ \\
Time Point : Previous Commitment & -3.883 & 1.759 & -2.208 & .027 \\
\hline
\end{tabular}

Table 10

Coefficients of linear model predicting identity fusion with supporters of the candidate as a function of wave time point, candidate preference, and previous candidate-related commitment.

\begin{tabular}{lcccc}
\hline & Estimate & Std. Error & $t$ & $p$ \\
\hline Intercept & 23.477 & 1.434 & 16.372 & $<.001$ \\
Time Point (post) & 5.601 & 1.557 & 3.597 & $<.001$ \\
Party Preference (Republican) & .475 & 2.195 & .217 & .829 \\
Prior Commitment & 19.800 & 1.384 & 14.301 & $<.001$ \\
Party Preference : Prior & & & & \\
Commitment & 4.905 & 2.364 & 2.075 & .038 \\
\hline
\end{tabular}

\section{Question Two: Effect of Identity Fusion on Participants' Ingroup Giving}

Impact of Fusion on Giving 
Table 11

Coefficients of linear model predicting ingroup giving as a function of identity fusion (mean-centered) with political party and supporters of the candidate, party preference, and time point.

\begin{tabular}{lcccc}
\hline & Estimate & Std. Error & $t$ & $p$ \\
\hline Intercept & 12.486 & .388 & 32.239 & $<.001$ \\
Party Preference (Republican) & .940 & .525 & 1.789 & .073 \\
Fusion Party & .012 & .011 & 1.076 & .282 \\
Fusion Candidate & .053 & .011 & 4.602 & $<.001$ \\
Time Point (post) & 1.295 & .419 & 3.090 & .002 \\
Fusion Party : Fusion Candidate & .0002 & .000 & 1.231 & .218 \\
Party preference : Fusion Party & .018 & .016 & 1.127 & .260 \\
Party preference : Fusion Candidate & -.036 & .015 & -2.408 & .016 \\
Fusion Candidate : Time Point & -.027 & .009 & -2.757 & .006 \\
Party preference : Fusion Party : & & & & .027 \\
Fusion Candidate & -.00005 & .000 & -2.216 & \\
\hline
\end{tabular}

